\title{
Anabases
}

ANABASES Traditions et réceptions de l'Antiquité

11 | 2010

Varia

\section{Marcelle ROBINSON, Schliemann's Silent Partner : Frank Calvert (1828-1908). Pionner, Scholar and Survivor}

Laure Caillot

\section{OpenEdition}

\section{Journals}

Édition électronique

URL : http://journals.openedition.org/anabases/915

DOI : 10.4000/anabases.915

ISSN : 2256-9421

\section{Éditeur}

E.R.A.S.M.E.

\section{Édition imprimée}

Date de publication : 1 mars 2010

Pagination : 283-284

ISSN : 1774-4296

\section{Référence électronique}

Laure Caillot, " Marcelle roBınson, Schliemann's Silent Partner: Frank Calvert (1828-1908). Pionner, Scholar and Survivor », Anabases [En ligne], 11 | 2010, mis en ligne le 01 septembre 2011, consulté le 22 septembre 2020. URL : http://journals.openedition.org/anabases/915 ; DOI : https://doi.org/10.4000/ anabases. 915

Ce document a été généré automatiquement le 22 septembre 2020

(c) Anabases 


\title{
Marcelle ROBINSON, Schliemann's Silent Partner : Frank Calvert (1828-1908). Pionner, Scholar and Survivor
}

\author{
Laure Caillot
}

\section{RÉFÉRENCE}

Marcelle ROBINSON, Schliemann's Silent Partner : Frank Calvert (1828-1908). Pionner, Scholar and Survivor, Philadelphie, Xlibris Corporation, 2006, $700 \mathrm{p}$.

24,64 dollars / ISBN 978-1413429152.

1 Marcelle Robinson nous propose une biographie riche et complète de Frank Calvert (1828-1908), le découvreur du site antique de Troie. Diplomate consulaire et archéologue anglais, il est à l'origine des fouilles du site d'Hissarlik, sept années avant les fouilles menées par Heinrich Schliemann. Le domaine d'Akca Koy fut acheté par son frère, Frederick Calvert et englobait la colline d'Hissarlik ; l'État turc acheta par la suite une partie du territoire. Frank Calvert mena donc ses propres prospections et fouilles sur la partie appartenant au domaine familial.

2 Cette étude rassemble les recherches conduites par l'auteure, depuis sa thèse de doctorat consacrée aux premières années de Calvert et poursuivies par la suite, ce qui lui permet de présenter une biographie complète. L'intérêt de cet ouvrage réside dans le fait qu'il s'agit de la seule étude consacrée à un personnage dont la postérité a en partie oublié le nom. En effet, une des premières reconnaissances publiques et modernes doit être attribuée à Vladimir Tolstikov qui mentionna son rôle dans ces découvertes dans le catalogue de l'exposition «Le trésor de Priam ", tenue à Moscou en 1996. Marcelle Robinson insiste d'ailleurs en introduction sur le fait qu'elle souhaite « restaurer Calvert à sa véritable place dans l'histoire et dans la carrière archéologique de Schliemann. » L'ouvrage s'articule autour de quarante-six chapitres qui détaillent notamment les différents épisodes de sa vie relatifs à ses travaux à Troie et à la relation 
entretenue avec Heinrich Schliemann. L'étude est complétée par un appendice comportant des illustrations ainsi que des documents d'archives (photographies, lettres, etc.).

3 Les quatre premiers chapitres dressent ainsi le cadre et le contexte familial dans lequel Frank Calvert a vécu le long du Bosphore des Dardanelles. On y découvre la vie de chacun des membres de la famille et la manière dont celle-ci acquit progressivement ses différentes propriétés foncières. Marcelle Robinson revient ainsi sur les premiers intérêts de Calvert pour l'archéologie locale suite à la découverte d'objets antiques sur leurs terrains. C'est à partir de 1847 que Calvert se lança dans l'exploration régulière de la colline Hissarlik et ses premiers écrits tendant progressivement à la reconnaissance du site de Troie furent publiés entre 1859 et 1862, même s'il en était assuré depuis de nombreuses années. C'est entre 1864 et 1868 qu'il commença à rechercher les fonds qui financeraient la suite de ses fouilles de la colline. La rencontre avec Schliemann fut décisive puisque Calvert n'eut pas de difficultés à le convaincre de s'intéresser à Hissarlik, ce qui renforçait d'autant plus les desseins de l'archéologue allemand, désireux de découvrir les lieux de l'épopée homérique. Cependant, les règlementations ottomanes en matière de fouilles archéologiques ralentirent leur projet. Les tensions entre les deux hommes prirent forme dès 1869 et se durcirent progressivement. Les confrontations furent importantes avec la publication en 1874 des Antiquités troyennes de Schliemann (chapitres 15-16,18) dans lequel l'archéologue ne prit guère en compte les travaux initiaux de Calvert. Même si l'ouvrage souligne essentiellement l'évolution des relations entre Calvert et Schliemann, l'auteure n'oublie pas néanmoins de souligner le reste de la carrière consulaire de Calvert, ainsi que de rappeler les différents contacts qu'il noua avec d'autres archéologues et collaborateurs scientifiques en Troade et dans le reste de l'Asie Mineure.

4 Aujourd'hui la collection d'antiquités que Calvert constitua durant toute sa vie a été éparpillée dans les musées de Turquie, de Londres et des États-Unis. De même, l'ensemble de ses lettres, notes, dessins et autres relevés ou photographies, à l'exception de quelques rares archives étudiées par l'auteure, a disparu, probablement lors du tremblement de terre de 1912. Ainsi, Marcelle Robinson conclut devant l'impossibilité d'affirmer si Calvert se destinait à la fin de sa vie à prouver, grâce à ses travaux personnels, comment Heinrich Schliemann avait pu s'approprier son travail et à rétablir ainsi sa propre place dans l'histoire de l'archéologie de la Troade.

\section{AUTEURS}

\section{LAURE CAILLOT}

Université de Provence

lcaillot@gmail.com 